Magy Abdelwahab, MD, $\mathrm{PhD}$

Michael Potegal, PhD

Elsa G. Shapiro, PhD

Igor Nestrasil, MD, PhD

Correspondence to

Dr. Abdelwahab:

magywahab@yahoo.com

Supplemental data at Neurology.org/ng

\section{Previously unrecognized behavioral phenotype in Gaucher disease type 3 OPEN}

\section{ABSTRACT}

Objective: To provide a comprehensive description of abnormal behaviors in patients with Gaucher disease type 3 (GD3) and relate these behaviors to demographic, neurodevelopmental, and neurologic characteristics.

Methods: Thirty-four Egyptian patients with GD3 (mean age of 7.9 years) were enrolled in the study. They were selected based on parent report and/or physician observation of one or more abnormal behaviors documented in 2 settings and by 2 different individuals and/or by video recording. Behaviors were grouped into 4 categories: Crying/Withdrawal, Impatience/Overactivity, Anger/Aggression, and Repetitive Acts. Baseline and follow-up 6-12 monthly neurologic evaluations included IQ assessment and an EEG. All patients were receiving enzyme replacement therapy (30-60 IU/kg every 2 weeks) and were followed for periods of 3-10 years.

Results: Supranuclear palsy of horizontal gaze, and of both horizontal and vertical gaze, bulbar symptoms, seizures, convergent strabismus, abnormal gait, and neck retroflexion were present in $97.1 \%, 50 \%, 55.9 \%, 29.4 \%, 29.4 \%, 20.6 \%$, and $4.4 \%$ of patients, respectively. The most abnormal behavioral features were excessive anger (88.2\%) and aggression (64.7\%), and both were significantly higher in males. Anger/Aggression scores were highly correlated with IQ but not with either EEG/Seizure status or neurologic signs.

Conclusions: We describe behavioral problems with a unique pattern of excessive anger and aggression in patients with GD3. Defining these components using quantitative behavioral scoring methods holds promise to provide a marker of neurologic disease progression and severity. Neurol Genet 2017;3:e158; doi: 10.1212/NXG.0000000000000158

\section{GLOSSARY}

ERT = enzyme replacement therapy; GBA = glucocerebrosidase; GD3 = Gaucher disease type 3; VSGP = vertical supranuclear gaze palsy.

Gaucher disease (GD) results from a glucocerebrosidase (GBA) mutation leading to glucocerebroside accumulation in multiple organs. Based on the genotype and/or the presence of neurologic involvement, 3 clinical subtypes are distinguished. Type 1 is nonneuronopathic; types 2 and 3 are neuronopathic. Type 3 (GD3) has a broad phenotypic spectrum ${ }^{1,2}$ with more than $50 \%$ of GD3 cases manifesting in infancy. The usual neurologic presentation includes developmental delay, supranuclear gaze palsy, bulbar symptoms, neurocognitive impairment, and seizures. Enzyme replacement therapy (ERT) has been reported to have no effect ${ }^{3,4}$ or lead to the stabilization $^{5,6}$ or even improvement of neurologic function. ${ }^{7}$

Reports on GD3 describe the physical manifestations and neurologic spectrum, but none have referred to the behavioral aspects of the disease. ${ }^{8-11}$ However, more than half of parents of children in our GD3 cohort complain about a set of abnormal behaviors, including extreme anger and aggression, persistent crying, excessive motor activity, and bizarre repetitive acts. The

From the Department of Pediatric Hematology (M.A.), Cairo University Pediatric Hospital, Egypt; and Program in Occupational Therapy (M.P.), and Division of Clinical Behavioral Neuroscience (E.G.S., I.N.), Department of Pediatrics, University of Minnesota, Minneapolis.

Funding information and disclosures are provided at the end of the article. Go to Neurology.org/ng for full disclosure forms. The Article Processing Charge was funded by the authors.

This is an open access article distributed under the terms of the Creative Commons Attribution-NonCommercial-NoDerivatives License 4.0 (CC BY-NC-ND), which permits downloading and sharing the work provided it is properly cited. The work cannot be changed in any way or used commercially without permission from the journal. 
Table 1 Demographic and descriptive data of patients with GD3

\begin{tabular}{|c|c|c|}
\hline Demographic data & No. of patients & $\%$ of tota \\
\hline \multicolumn{3}{|l|}{ Sex prevalence } \\
\hline Male & 21 & 61.8 \\
\hline Female & 13 & 38.2 \\
\hline Consanguinity ${ }^{a}$ & 30 & 88.2 \\
\hline \multicolumn{3}{|l|}{ Age, $y$, mean $\pm S D$} \\
\hline Current & $8.7 \pm 5.1$ & \\
\hline At diagnosis & $1.0 \pm 0.4$ & \\
\hline Family history of previous induced abortions $s^{b}$ & 6 & 17.6 \\
\hline $\begin{array}{l}\text { Similarly affected sibling/family member } \\
\text { (dead or alive) }\end{array}$ & 19 & 55.8 \\
\hline Patients receiving imiglucerase (ERT) & 32 & 94.1 \\
\hline Patients receiving velaglucerase (ERT) & 2 & 5.9 \\
\hline Duration of ERT, $y$, mean $\pm S D$ & $6.9 \pm 4.9$ & \\
\hline $\begin{array}{l}\text { Improvement of neurologic and/or other } \\
\text { systems }^{c} \text { on ERT }\end{array}$ & 27 & 79.4 \\
\hline $\begin{array}{l}\text { Worsening of neurologic and/or other } \\
\text { systems }{ }^{c} \text { on ERT }\end{array}$ & 7 & 20.6 \\
\hline
\end{tabular}

Abbreviations: ERT = enzyme replacement therapy; GD3 = Gaucher disease type 3. Four children with severe GD3 physical phenotype had abnormal facies characterized by low set ears, hypertelorism, and ptosis. Three children with GD3 underwent splenectomy. ${ }^{a}$ Consanguinity: first-degree maternal or paternal cousins.

${ }^{b}$ Induced abortion when the fetus was tested as homozygous for L444P by chorionic villous sampling.

${ }^{c}$ Other systems: pulmonary (recurrent wheezy chest and chest infections), mesenteric and mediastinal lymphadenopathy, bone complications (bone aches, fractures, and avascular necrosis), kyphoscoliosis, and dental problems.

treating physician (M.A.) has noted behavioral changes and tendency for aggressive behavior, ${ }^{2,12}$ but other than those preliminary reports, the behavioral phenotype of GD3 has not been systematically studied and is currently unknown.

The aims of this retrospective exploratory study were to characterize these behavioral patterns and relate them to neurodevelopmental and neurologic characteristics. Such foundational knowledge will permit the development of working hypotheses for a subsequent prospective study. Based on a detailed single clinical observation as well as neurologic and treatment-related response, we describe the abnormal behaviors occurring in the cohort of 34 Egyptian patients diagnosed with GD3.

METHODS Standard protocol approvals, registrations, and patient consents. The protocol was approved by the local Ethical Committee. All patients/parents/legal guardians of patients provided their written informed consent.

Patients. Thirty-four Egyptian patients with GD3 whose parents reported and/or physician (M.A.) observed one or more abnormal behaviors were enrolled in the study, while those who did not show any behavioral abnormalities were excluded. The GD3 group showing behavioral problems represents 52\% of the Cairo University Pediatric Hospital GD3 cohort containing 65 patients in total. Definitive diagnosis of GD was typically made between 9 and 15 months of age from reduced leukocyte $\beta$-GBA activity $(<1 \mu \mathrm{mol} / \mathrm{g}$ of protein/h); type 3 diagnosis is determined by genotyping and/or the presence of neurologic manifestation and persistence beyond infancy. Genetic testing of 27 children was performed by full sequencing of the gene for common mutations associated with GD3. All were homozygous for L444P.

Since diagnosis, the patients have been followed for periods of 3-10 years. They underwent systematic neurologic re-evaluation at 6-month intervals. The data presented here were derived from the retrospective review of the records of a single evaluation of each child between 2006 and 2015 . The patients' demographic and descriptive data are shown in table 1.

Procedures. Abnormal behaviors. Table 2 shows the list of abnormal behaviors, which was developed through observation of patients in the clinic and discussions with their parents about frequency and variation among these behaviors that occurred outside the clinic. Therefore, some descriptors and categories may be colloquial and culture specific. Behaviors of 18 patients were documented by video recording; 12 of these videos were reviewed with coauthors (E.G.S. and I.N.) to identify, confirm, and categorize behaviors. All behaviors included in this report were documented in at least 2 settings, including hospital (observation by the examining physician during a clinic visit), school, and/or home. All these behaviors were witnessed by more than one person, including parents, siblings, peers, treating physician, and sometimes strangers who reported it to parents.

Behaviors were grouped into 4 categories based on similarity of form and/or function, co-occurrence, and/or sequential occurrence. Scales for each category consisted of 1 point for each of the behaviors assigned to that category: Anger/Aggression (0-14), Impatience/Overactivity (0-3), Crying/Withdrawal (0-4), and Repetitive Acts (0-3). The larger number of Anger/Aggression items represents both the diversity of behaviors in this category and their salience to observers.

Cognitive, EEG, and clinical neurologic assessment. The same clinician (M.A.) conducted baseline and follow-up neurologic evaluations every 6-12 months, individualized according to the patient's condition. Other evaluations included IQ assessment and an EEG recorded under standard International 10-20 system. Wechsler scales for preschool, school age, and adult subjects were used to assess IQ. For children younger than 4 years, the Vineland Adaptive Behaviour Scales II was used to estimate IQ. ${ }^{13}$

EEGs were graded as follows: $0=$ normal, $1=$ nonepileptiform abnormality, and 2 = epileptiform abnormality. ${ }^{14}$ If clinical seizures were present, an additional point was given. The continuity of this 4-point scale was indicated by the observation that the percentage of patients with EEG scores of 0,1 , and 2 who were known to have seizures was $8 \%, 20 \%$, and $50 \%$, respectively. The neurologic signs listed in table e-1 at Neurology.org/ng were scored as absent or present $(0,1)$.

Statistical analysis. Descriptive statistics were used to describe results by percentages, mean values, and SDs. To assess changes in behavior with age, the symptom profiles of the children were ordered by age and examined for patterns of occurrence. Nonparametric Spearman rank-order correlation was used to test for association between variables; the 


\begin{tabular}{|c|c|c|c|c|}
\hline \multirow{2}{*}{$\begin{array}{l}\text { Table } 2 \\
\text { Descriptc }\end{array}$} & \multicolumn{4}{|c|}{$\begin{array}{l}\text { Abnormal behaviors grouped by category: Descriptors, number, and } \\
\text { percentages of patients with Gaucher disease type } 3 \text { showing } \\
\text { abnormal behavior }\end{array}$} \\
\hline & & Definitions/examples & No. & $\%$ \\
\hline \multicolumn{5}{|c|}{ Anger/Aggression } \\
\hline \multicolumn{2}{|c|}{ Excessive anger } & $\begin{array}{l}\text { Inappropriately intense anger to } \\
\text { nonprovocative or trivially provocative } \\
\text { events }\end{array}$ & 30 & 88.2 \\
\hline \multicolumn{2}{|c|}{ Physically aggressive } & $\begin{array}{l}\text { Includes grabbing other children by the } \\
\text { hair, hitting, biting, and strangling }\end{array}$ & 22 & 64.7 \\
\hline \multicolumn{2}{|c|}{ Oppositional } & Defies adults & 20 & 58.8 \\
\hline \multicolumn{2}{|c|}{ Verbally aggressive } & Insults others & 17 & 50.0 \\
\hline \multicolumn{2}{|c|}{ Age-inappropriate tantrums } & $\begin{array}{l}\text { Tantrums occurring after age } 4 \text {, lasting } \\
10-15 \text { min in the clinic and, reportedly, } \\
\text { for hours at home }\end{array}$ & 15 & 44.1 \\
\hline \multicolumn{2}{|c|}{ Explosive temper } & Sudden outbursts of anger & 13 & 38.2 \\
\hline \multicolumn{2}{|c|}{ Unpredictable aggression } & $\begin{array}{l}\text { Brief, sudden, and surprising physical } \\
\text { attacks (e.g., biting) in the context of } \\
\text { otherwise amicable social interaction }\end{array}$ & 12 & 35.3 \\
\hline \multicolumn{2}{|c|}{ Proactive aggression } & $\begin{array}{l}\text { Smiling or laughing while hitting or } \\
\text { committing other aggressive acts }\end{array}$ & 12 & 35.3 \\
\hline \multicolumn{2}{|c|}{ Touchy } & Easily annoyed by others & 9 & 26.5 \\
\hline \multicolumn{2}{|c|}{ Blames } & $\begin{array}{l}\text { Accuses others of making mistakes and/ } \\
\text { or of misbehaving }\end{array}$ & 8 & 23.5 \\
\hline \multicolumn{2}{|l|}{ Curses } & Uses obscenities & 8 & 23.5 \\
\hline \multicolumn{2}{|c|}{ Vindictive } & $\begin{array}{l}\text { Takes revenge for real or imagined } \\
\text { provocations over hours or days }\end{array}$ & 8 & 23.5 \\
\hline \multicolumn{2}{|c|}{ Threatens } & Threats to injure, kill, or "slaughter" & 8 & 23.5 \\
\hline \multicolumn{2}{|c|}{ Self-injurious } & Slaps own face in frustration & 6 & 17.6 \\
\hline \multicolumn{5}{|c|}{ Impatience/Overactivity } \\
\hline \multicolumn{2}{|c|}{ Interrupts others } & Speaks out while others are talking & 10 & 29.4 \\
\hline \multicolumn{2}{|c|}{ Impatient } & Cannot wait his/her turn & 8 & 23.5 \\
\hline \multicolumn{2}{|c|}{ Excess activity/hyposomnia } & $\begin{array}{l}\text { Continual pacing, climbing up and down } \\
\text { chairs and other objects; never } \\
\text { appearing to tire; sleeping for hours less } \\
\text { than typical for age and sometimes } \\
\text { complete lack of sleep }\end{array}$ & 5 & 14.7 \\
\hline \multicolumn{5}{|c|}{ Crying/Withdrawal } \\
\hline \multicolumn{2}{|c|}{ Demanding } & $\begin{array}{l}\text { Nags, makes excessive demands on } \\
\text { others }\end{array}$ & 20 & 58.8 \\
\hline \multicolumn{2}{|c|}{ Social withdrawal } & Retreats from social interaction & 17 & 50.0 \\
\hline \multicolumn{2}{|l|}{ Clings } & Age-inappropriate clinging to caretaker & 8 & 23.5 \\
\hline \multicolumn{2}{|c|}{ Cries excessively } & Continuous crying, with or without tears & 7 & 20.6 \\
\hline \multicolumn{5}{|c|}{ Repetitive Acts } \\
\hline \multicolumn{2}{|c|}{ Recurring behaviors } & $\begin{array}{l}\text { Stereotypies, punding, shredding paper } \\
\text { and plastic bags, tying-untying hair in } \\
\text { a knot, pacing up and down in a room, } \\
\text { and repeating same housecleaning } \\
\text { movements for hours }\end{array}$ & 10 & 29.4 \\
\hline \multicolumn{2}{|c|}{ Object obsession } & Obsessed with a specific object & 6 & 17.6 \\
\hline \multicolumn{2}{|c|}{ Hyperphagia } & Obsessed with food, compulsive eating & 4 & 8.8 \\
\hline
\end{tabular}

Descriptors are ordered by category and by prevalence within category.

Mann-Whitney $U$ test was used to assess male-female differences. Neurologic signs that were significantly associated with one or more behavior categories were identified by the Pratt measure ${ }^{15}$ in exploratory multiple regressions of behavior on the full set of signs. Significance values were adjusted for multiple tests using the false discovery rate protocol. ${ }^{16}$
RESULTS All enrolled children presented initially with organomegaly, motor, and rarely global delay. Nineteen children had neurologic symptoms initially; the other 15 developed neurologic symptoms subsequently. Prevalence of neurologic manifestations noted in our type $3 \mathrm{GD}$ cohort is shown in table e-1. Thirty-two patients were started on ERT, imiglucerase (30-60 IU/kg every 2 weeks) and 2 patients on velaglucerase alfa $(60 \mathrm{IU} / \mathrm{kg}$ every 2 weeks). Patients received ERT regularly except during the 2-year worldwide enzyme shortage in 2009-2011.

IQ. The IQ for the group was $71.1 \pm 10.5$ (mean \pm $\mathrm{SD})$; for females and males, it was $74.3 \pm 8.9$ and $68.9 \pm 11.0$, respectively. These results suggest borderline intellectual functioning overall for this group. Compared with population norms, they were 2 SDs below the mean. Only 1 patient had an IQ in the average range $(>85)$.

EEG status/clinical seizures. Five patients (14.7\%) had EEG ratings of 1; 16 (47\%) had EEG ratings of 2. Half of those with ratings of 2 had clinical seizures. Initial EEG recording showed a clear epileptic focus in 10 children, 8 of whom had clinical seizures that ranged from focal or focal with secondary generalization to generalized or myoclonic types. Seizure frequency varied from 1 to 2 per month to several per day. Patients were treated with valproic acid at doses up to $60 \mathrm{mg} / \mathrm{kg} / \mathrm{d}$ with variable seizure control. EEG epileptic foci resolved in 4 children spontaneously in later childhood over a 3-year period.

Qualitative behavioral observations. A wide range of abnormal behaviors was observed. The frequency varied from daily to monthly depending on the type and precipitating factor(s) such as a younger sibling smiling at the patient or touching him, but in many children, they have been going on for years. Table 3 displays the number (and percentage) of patients with GD3 showing each abnormal behavior, with examples, grouped by category.

Anger/Aggression. These behaviors were directed to peers, siblings, parents, and other adults/authority figures including the treating physician. Angry and aggressive acts were the most common, prominent, and troublesome of the abnormal behaviors and were reported to have had a major negative effect on patients' and parents' quality of life. For 23 (69.7\%) patients, these behaviors were the parents' main concern or sole complaint.

Based on the median age at which the various aggressive behaviors appeared, tantrums past toddler age, oppositional behavior, physical aggression, and angry self-injury appeared earliest to develop; these behaviors tended to be the most prevalent across 
Table 3 Descriptive statistics for quantified behavioral observations

$\begin{array}{llll} & \begin{array}{l}\text { Female }(\mathrm{n}=13), \\ \text { mean } \pm \text { SD }\end{array} & \begin{array}{l}\text { Male }(\mathrm{n}=21), \\ \text { mean } \pm \text { SD }\end{array} & \begin{array}{l}\text { Total }(\mathrm{N}=34), \\ \text { mean } \pm \text { SD }\end{array} \\ \text { Age, } \mathbf{y} & 9.7 \pm 6.2 & 8.1 \pm 4.3 & 8.7 \pm 5.1 \\ \text { Anger/Aggression (0-14 scale) } & 3.3 \pm 2.0 & 7.0 \pm 3.3 & 5.5 \pm 3.4 \\ \text { Impatient/Overactive (0-3 scale) } & 0.2 \pm 0.4 & 1.0 \pm 1.1 & 0.7 \pm 1.0 \\ \text { Crying/Withdrawn (0-4 scale) } & 1.8 \pm 1.0 & 1.4 \pm 0.9 & 1.5 \pm 1.0 \\ \text { Repetitive Acts (0-3 scale) } & 0.4 \pm 0.8 & 0.7 \pm 0.9 & 0.6 \pm 0.9\end{array}$

the group. Unpredictable and proactive aggression, using obscenities and vindictive behavior, tended to appear subsequently and were less prevalent; being touchy/easily annoyed, explosive temper, blaming others, verbal aggression and insults, and homicidal

\section{Figure Age trends for all 4 abnormal behavior categories}

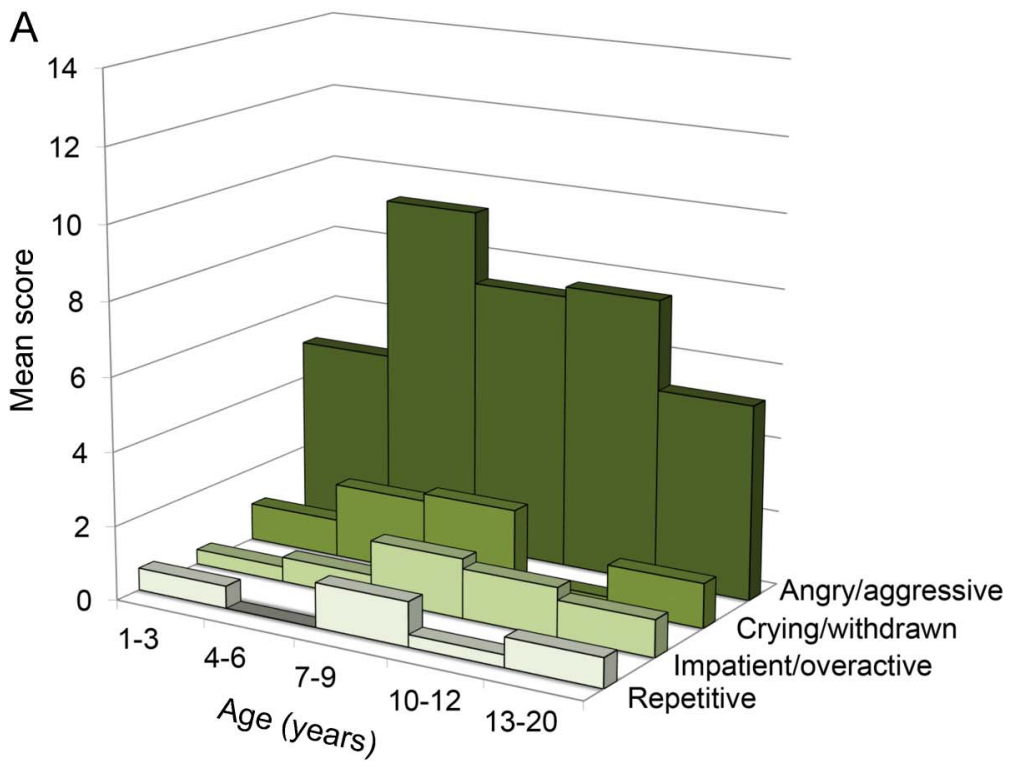

B

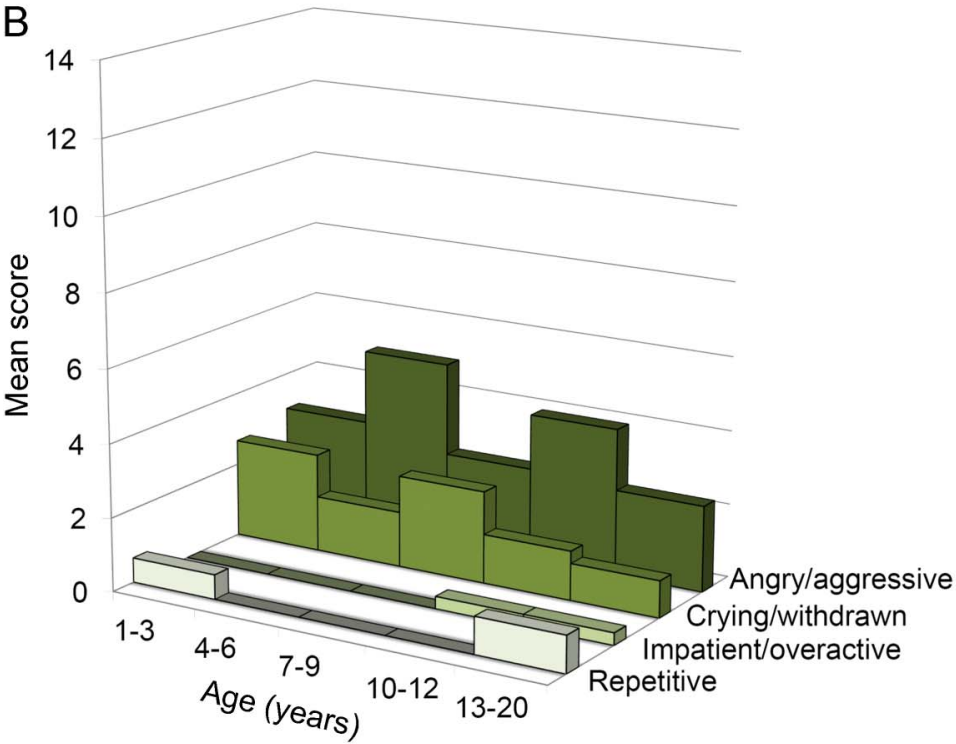

(A) Males. (B) Females. threats were generally the last to appear and tended to be least prevalent.

Impatience/Overactivity. Parents reported that a child's overactivity in social gatherings was disruptive, embarrassing, tiring, and sometimes impossible to deal with.

Crying/Withdrawal. Children with these characteristics were wary of strangers, socially withdrawn, and clung to and were demanding of their parents.

Repetitive Acts. These varied in type and complexity; they often could not be interrupted.

Quantitative behavioral results. Anger/Aggression. All but one of the 34 subjects had scores $\geq 3$ on the Anger/ Aggression measure. Mean values for this measure, calculated for successive 3-year periods, increased for females and almost doubled for males from value at 1-3 years of age to a peak at 4-6-year-olds, then fell back to near values observed at 1-3-year-olds by adolescence (figure). Males also showed higher Anger/ Aggression than females $(U=162, p<0.02$, table $3)$. Anger/Aggression scores were highly negatively correlated with IQ but not with either the EEG/ Seizure status or neurologic signs (table 4). Anger/ Aggression scores were correlated with Impatient/ Overactive scores $(r=0.45, p<0.01)$.

Impatience/Overactivity. Four of the seven 7-9-yearolds were reported to show one or more signs of Impatience/Overactivity, which was the age range for highest scores on this scale. Males were more Impatient/Overactive than females according to a Mann-Whitney test $(U=136.5, p<0.02)$. Across all subjects, there was a near-significance for Impatience/Overactivity scores to be correlated with vertical supranuclear gaze palsy (VSGP) (table 4).

Crying/Withdrawal. One or more Crying/Withdrawal behaviors were shown by 10 of the 12 youngest children (1-5 years old) in contrast to Impatient/Overactive and Repetitive Acts, which were each shown by only 2 of these 12 children. These scores appeared to decline after age 9 (figure). Crying/Withdrawn scores were nonsignificantly higher in females (figure). Over all subjects, these scores were associated with EEG/Seizure status (table 4). Crying/Withdrawal scores were not correlated with any of the other 3 behavior categories.

Repetitive Acts. Repetitive Act scores were nonsignificantly higher for males. These scores were correlated with Impatient/Overactive scores $(r=0.47, p<$ 0.005). Repetitive Act scores were also correlated with ptosis $(r=0.42, p<0.02)$; correlations with EEG status and with strabismus tended to approach significance as showed in table 4 .

DISCUSSION Abnormal behavioral features in the patients with GD3 have not been described in detail. The largest GD type 3 study analyzing the 
Table 4 EEG/Seizure status and neurologic sign correlations with behavior categories

$\begin{array}{lllll} & \text { Anger/Aggression } & \text { Repetitive Acts } & \text { Cry/Withdrawal } & \text { Impatient/Overactive } \\ \text { IQ } & -0.52^{* * *} & -0.21 & -0.16 & -0.06 \\ \text { Strabismus } & -0.18 & 0.38^{*} & 0.11 & 0.18 \\ \text { Ptosis (with abnormal facies) } & -0.12 & 0.42^{* *} & 0.31^{*} & -0.01 \\ \text { EEG/Seizure status } & 0.08 & 0.34 * & 0.34 * & 0.26 \\ \text { VSGP } & 0.29 & 0.07 & -0.20 & 0.31^{*}\end{array}$

Abbreviation: VSGP $=$ vertical supranuclear gaze palsy. $* p<0.1, * * p<0.05, * * * p<0.02$.

Neurological Outcomes Subregistry of the International Collaborative Gaucher Group, which included 40/131 Egyptian patients mostly homozygous L444P, contained no reference to abnormal behaviors. ${ }^{17}$ The prevalence of supranuclear gaze palsy and convergent strabismus in our study cohort resemble the registry data, but bulbar symptoms and seizures were more prevalent in our cohort, suggesting more severe CNS involvement.

Abnormal behaviors that occur in various genetic diseases and other clinical conditions include changes in attention and activity as well as simple and complex repetitive acts (e.g., motor stereotypies, object manipulation, and compulsive acts).$^{18}$ However, the profile of behavioral abnormalities varies in different clinical conditions. Some of these behaviors appear in many different conditions, presumably due to a confluence of genetic/developmental dysfunction in commonly affected brain systems together with the shaping of behavior by responses from caregivers and others. ${ }^{19}$

Our cohort showed a wide spectrum of behavioral abnormalities. Angry and aggressive behaviors were the most prevalent and the greatest cause of concern. These included both reactive and proactive aggression. Reactive aggression is a response to perceived provocation or challenge to personal autonomy or social norms and is often accompanied by anger. Proactive aggression, such as deliberate harassment and bullying, without provocation, is committed to dominate others and/or for material gain, e.g., attention, control of toys etc. ${ }^{20}$ Children have been observed to smile or laugh while committing proactive aggression. ${ }^{21,22}$

The sequence in which tantrums, oppositional behavior, and physical aggression develop early; proactive aggression, the use of obscenities and vindictive behavior appear later, and blaming others, verbal aggression and insults, and homicidal threats are last to appear; reflects the children's increasing cognitive and verbal capacity. However, the progressive increases in angry and aggressive behaviors through age 4-6 differ from the normal trajectory. Very large scale studies with hundreds to thousands of children have determined that trajectories of physical aggression typically increase up through age 3 , then decline. ${ }^{23}$ Although the greater aggression in males was to be expected, ${ }^{24}$ the overall anger intensity and aggression severity in these patients with GD3 appear to be considerably greater than normal and significantly affect quality of life for them and their parents. We identified a strong correlation between IQ and the Anger/Aggression scale, which replicates the relationship found in other neurodegenerative disease conditions. ${ }^{25,26}$ Whether other features of GD3, such as physical disability/discomfort, exacerbate anger and aggression remains to be determined.

Elevated rates of EEG abnormality and frank clinical seizures are well known in children with GD3. In general, EEG abnormalities and clinical seizures are associated with a range of behavioral problems, most often internalizing anxiety and depression, but also extending to externalizing inattention and acting out. ${ }^{27}$ Some forms of juvenile epilepsy remit spontaneously during development. ${ }^{28-30}$ At least 4 patients with GD3 seen in the Cairo Hospital have had apparently spontaneous normalization of EEG and/or remission of seizures in later childhood. These observations raise the question of whether changes in EEG might be associated with reductions in abnormal behavior.

Anger/Aggression and Repetitive Acts were both significantly associated with Impatient/Overactive behaviors. Such associations are common across clinical conditions..$^{24}$ On the other hand, these 3 categories had different patterns of association with other independent variables: While Impatient/ Overactive behaviors were just marginally associated with VSGP, higher Anger/Aggression was strongly associated with lower IQ as noted, while Repetitive Acts correlated with the EEG/Seizure score and with 2 neurologic signs. One possible interpretation of this pattern is that a primary dysfunction in corticobasal ganglia pathways regulating attention/activity reduces both inhibitory prefrontal control over several different neurologic subsystems such as temporal lobe/hypothalamic circuits that control anger and aggression ${ }^{31}$ and 
dopaminergic mesolimbic circuits that foster the repetition of behaviors that are reinforcing. ${ }^{32,33} \mathrm{Be}$ haviors in GBA1 genotype D409V/null mice seem similar in that according to their handlers. Mice were hyperactive, jumpy, and aggressive toward other mice and humans, biting far more often than wild-type mice or mice with other GBA1 mutations. ${ }^{34}$

Crying/Withdrawal behaviors appeared early in development and were not associated with any of the other behavioral patterns. Crying and social withdrawal are internalizing behaviors to which females are more susceptible than males, ${ }^{35}$ and the mean Cry/Withdrawal score was the only one that was higher for females, albeit nonsignificantly. These behaviors were associated with the EEG/Seizure score. Sixty-two percent of patients had abnormal EEGs and/or seizures consistent with the neurologic involvement of GD3. This is far higher than the rate of EEG abnormalities in childhood populations. ${ }^{36}$ EEG abnormalities and clinical seizures are associated with a range of behavioral problems, most often internalizing anxiety and depression ${ }^{27}$ which may relate to the Cry/Withdrawal pattern of GD3. Spontaneous recovery from childhood seizures is well known. ${ }^{30}$ Such recovery may contribute to the reduction of the Crying/Withdrawal pattern after 7-9 years of age.

That these behaviors are intrinsic to the disease and not due to additional shared genes/inherited traits is suggested by the observation that these patients, while derived from consanguineous matings, are not from a tightly inbred population with a founder. They are from small, independent (at least for many generations) groups.

For this initial study, we assessed behaviors with descriptors developed in collaboration with some parents and therefore most likely to be recognized and understood by other parents within the Egyptian culture. This approach has produced statistically significant results but may limit their replicability. Behaviors were recorded as present/absent for simplicity, but frequency measures might provide data for more sensitive analyses of behavioral profiles and correlations with neurologic function. The use of cluster analyses to determine data-driven groupings of behavior was precluded by systematic shifts in behaviors with age. The abnormal development of anger and aggression in children with GD3 was highlighted by comparison with published data on normal developmental trajectories of these behaviors. As noted below, comparison of affected children's behaviors to that of their healthy siblings would provide a useful control for family-related variables in the future.

This retrospective study has raised questions about developmental changes with age, disease progression, and treatment effects in GD3 that can only be answered by longitudinal follow-up. This work should involve standardized scales of aggression and other behaviors that are available in Arabic translation, e.g., the Child Behavior Checklist ${ }^{37}$ to track behavior and neurologic function together over time. Standardized scales would also facilitate the application of The Diagnostic and Statistical Manual of Mental Disorders, 5th edition or the International Classification of Diseases, 10th revision diagnostic categories, e.g., the Impatient/Overactive category may well correspond to attention-deficit/hyperactivity disorder. Future studies should also include comparisons with healthy siblings or neurotypicals as well as with those with the nonneuronopathic GD type 1 who have equivalent medical problems.

Abnormal behaviors are a phenotypic feature of GD3 in the Egyptian cohort, the largest GD3 cohort reported worldwide. The behavior patterns are clearly complex. Our working hypothesis is that they may involve a Crying/Withdrawal component that manifests early, affects both males and females, and may relate to epileptiform activity in the brain. A second, apparently independent component of Impatience/ Overactivity primarily involves males, can be associated with bizarre repetitive acts and/or highly salient intense anger and severe aggression. The repetitive acts may be associated with several neurologic signs. The Anger/Aggression component, which may start later and persist longer than Crying/Withdrawal, is clearly associated with lower cognitive ability.

These components defined by quantitative behavioral scoring methods might serve as markers of neurologic disease progression and severity. EEG recording together with structural and functional brain imaging methods can provide insight into the localization of the underlying pathophysiologic processes in Gaucher type 3, which would guide future treatments targeting the CNS disease.

\section{AUTHOR CONTRIBUTIONS}

Magy Abdelwahab, study concept and design, recruited and studied the patients and gathered all data, interpreted the data, and edited the manuscript. Michael Potegal, analysis and interpretation of data and writing and editing the manuscript. Elsa Shapiro, analysis and interpretation of data and editing and critical revision of manuscript for intellectual content. Igor Nestrasil, analysis and interpretation of data and writing and editing the manuscript.

\section{ACKNOWLEDGMENT}

The authors are grateful to the patients and their families who participated in this study as well as the Center for Neurobehavioral Development (CNBD) for providing the spaces for the video assessments with coauthors (E.G.S. and I.N.). They thank Dr. Robin Rumsey for her help in distinguishing behavioral abnormalities during initial video assessments; Dr. Greg Grabowski for the observations of the genetically intrinsic nature of the behavioral abnormalities; Dr. Pramod Mistry, Yale University, for help with GBA1 sequencing; Dr. Khaled Eid for technical help; Dr. Mohamed Abd Elmonem, Cairo University, Egypt, for help with GBA1 genotyping; and Genzyme A Sanofi Company, Shire Plc, and the Hope project for providing ERT product. 


\section{STUDY FUNDING}

No targeted funding reported.

\section{DISCLOSURE}

Dr. Magy Abdelwahab has received travel funding from a nonprofit entity. Dr. Michael Potegal reports no disclosures. Dr. Elsa Shapiro has served on scientific advisory boards for ReGenXBio, Armagen, Shire, SOBI, BioMarin, and Eloxx; has received travel funding/speaker honoraria from Shire and BioMarin; has been a consultant for ReGenXBio, Armagen, Shire, SOBI, BioMarin, Eloxx, Alexion, Chiesi, BluebirdBio, Sangamo, Aeglea, and Lysogene; and is a partner in Shapiro \& Delaney, LLC. Dr. Igor Nestrasil has been a consultant for Armagen, BioMarin, Lysogene, ReGenXBio, and ICON and has received research support from Shire, Genzyme, BioMarin, NIH, The Penn Medicine Orphan Disease Center, and the University of Pennsylvania. Go to Neurology. org/ng for full disclosure forms.

Received November 23, 2016. Accepted in final form April 7, 2017.

\section{REFERENCES}

1. Benko W, Ries M, Wiggs EA, Brady RO, Schiffmann R, Fitzgibbon EJ. The saccadic and neurological deficits in type 3 Gaucher disease. PLoS One 2011;6:e22410.

2. Abdelwahab M, Blankenship D, Schiffmann R. Long-term follow-up and sudden unexpected death in Gaucher disease type 3 in Egypt. Neurol Genet 2016;2:e55. doi: 10. 1212/NXG.0000000000000055.

3. Erikson A, Bembi B, Schiffmann R. Neuronopathic forms of Gaucher's disease. Baillieres Clin Haematol 1997;10: 711-723.

4. Campbell PE, Harris CM, Vellodi A. Deterioration of the auditory brainstem response in children with type 3 Gaucher disease. Neurology 2004;63:385-387.

5. Altarescu G, Hill S, Wiggs E, et al. The efficacy of enzyme replacement therapy in patients with chronic neuronopathic Gaucher's disease. J Pediatr 2001;138:539-547.

6. Erikson A, Astrom M, Mansson JE. Enzyme infusion therapy of the Norrbottnian (type 3) Gaucher disease. Neuropediatrics 1995;26:203-207.

7. Vellodi A, Bembi B, de Villemeur TB, et al. Management of neuronopathic Gaucher disease: a European consensus. J Inherit Metab Dis 2001;24:319-327.

8. Choy FY, Zhang W, Shi HP, et al. Gaucher disease among Chinese patients: review on genotype/phenotype correlation from 29 patients and identification of novel and rare alleles. Blood Cells Mol Dis 2007;38:287-293.

9. Goker-Alpan O, Wiggs EA, Eblan MJ, et al. Cognitive outcome in treated patients with chronic neuronopathic Gaucher disease. J Pediatr 2008;153:89-94.

10. Davies EH, Erikson A, Collin-Histed T, Mengel E, Tylki-Szymanska A, Vellodi A. Outcome of type III Gaucher disease on enzyme replacement therapy: review of 55 cases. J Inherit Metab Dis 2007;30:935-942.

11. Tajima A, Yokoi T, Ariga M, et al. Clinical and genetic study of Japanese patients with type 3 Gaucher disease. Mol Genet Metab 2009;97:272-277.

12. Abdelwahab M. Management of type 3 Gaucher disease. Int J Clin Rev 2012;10:93-99.

13. Delaney KA, Rudser KR, Yund BD, Whitley CB, Haslett PA, Shapiro EG. Methods of neurodevelopmental assessment in children with neurodegenerative disease: Sanfilippo syndrome. JIMD Rep 2014;13:129-137.

14. Noachtar S, Binnie C, Ebersole J, Mauguiere F, Sakamoto A, Westmoreland B. A glossary of terms most commonly used by clinical electroencephalographers and proposal for the report form for the EEG findings. The International Federation of Clinical Neurophysiology. Electroencephalogr Clin Neurophysiol Suppl 1999;52:21-41.

15. Thomas DR, Hughes E, Zumbo BD. On variable importance in linear regression. Soc Indic Res 1998; 45:253-275.

16. Benjamini Y, Drai D, Elmer G, Kafkafi N, Golani I. Controlling the false discovery rate in behavior genetics research. Behav Brain Res 2001;125:279-284.

17. Tylki-Szymanska A, Vellodi A, El-Beshlawy A, Cole JA, Kolodny E. Neuronopathic Gaucher disease: demographic and clinical features of 131 patients enrolled in the International Collaborative Gaucher Group Neurological Outcomes Subregistry. J Inherit Metab Dis 2010;33:339-346.

18. Moss J, Oliver C, Arron K, Burbidge C, Berg K. The prevalence and phenomenology of repetitive behavior in genetic syndromes. J Autism Dev Disord 2009;39: 572-588.

19. Muehlmann AM, Lewis MH. Abnormal repetitive behaviours: shared phenomenology and pathophysiology. J Intellect Disabil Res 2012;56:427-440.

20. Hubbard JA, McAuliffe MD, Morrow MT, Romano LJ. Reactive and proactive aggression in childhood and adolescence: precursors, outcomes, processes, experiences, and measurement. J Pers 2010;78:95-118.

21. Arsenio W, Cooperman S. Children's conflict-related emotions: implications for morality and autonomy. New Dir Child Dev 1996:25-39.

22. Benenson JF, Carder HP, Geib-Cole SJ. The development of boys' preferential pleasure in physical aggression. Aggress Behav 2008;34:154-166.

23. Fanti KA, Henrich CC. Trajectories of pure and cooccurring internalizing and externalizing problems from age 2 to age 12: findings from the National Institute of Child Health and Human Development Study of Early Child Care. Dev Psychol 2010;46:1159-1175.

24. Potegal M, Archer J. Sex differences in childhood anger and aggression. Child Adolesc Psychiatr Clin N Am 2004; 13:513-528, vi-vii.

25. Oliver C, Petty J, Ruddick L, Bacarese-Hamilton M. The association between repetitive, self-injurious and aggressive behavior in children with severe intellectual disability. J Autism Dev Disord 2012;42:910-919.

26. Schroeder SR, Marquis JG, Reese RM, et al. Risk factors for self-injury, aggression, and stereotyped behavior among young children at risk for intellectual and developmental disabilities. Am J Intellect Dev Disabil 2014; 119:351-330.

27. Dunn DW, Austin JK, Perkins SM. Prevalence of psychopathology in childhood epilepsy: categorical and dimensional measures. Dev Med Child Neurol 2009; 51:364-372.

28. Cavazzuti GB, Cappella L, Nalin A. Longitudinal study of epileptiform EEG patterns in normal children. Epilepsia 1980;21:43-55.

29. Loiseau P, Pestre M, Dartigues JF, Commenges D, Barberger-Gateau C, Cohadon S. Long-term prognosis in two forms of childhood epilepsy: typical absence seizures and epilepsy with rolandic (centrotemporal) EEG foci. Ann Neurol 1983;13:642-648.

30. Sillanpaa M, Jalava M, Kaleva O, Shinnar S. Long-term prognosis of seizures with onset in childhood. N Engl J Med 1998;338:1715-1722. 
31. Potegal M. Temporal and frontal lobe initiation and regulation of the top-down escalation of anger and aggression. Behav Brain Res 2012;231:386-395.

32. Fasano A, Petrovic I. Insights into pathophysiology of punding reveal possible treatment strategies. Mol Psychiatry 2010;15:560-573.

33. McBride SD, Parker MO. The disrupted basal ganglia and behavioural control: an integrative cross-domain perspective of spontaneous stereotypy. Behav Brain Res 2015;276: $45-58$.

34. Dai M, Liou B, Swope B, et al. Progression of behavioral and CNS deficits in a viable Murine model of chronic neuronopathic Gaucher disease. PLoS One 2016;11: e0162367.
35. Zahn-Waxler C, Crick NR, Shirtcliff EA, Woods KE. The origins and development of psychopathology in females and males. In: Cicchetti D, Cohen DJ, editors. Developmental Psychopathology: Volume 1 Theory and Method. Hoboken: Wiley; 2006.

36. Shelley BP, Trimble MR. "All that spikes is not fits," mistaking the woods for the trees: the interictal spikesan "EEG chameleon" in the interface disorders of brain and mind: a critical review. Clin EEG Neurosci 2009;40: 245-261.

37. Achenbach TM, Ruffle TM. The child behavior checklist and related forms for assessing behavioral/emotional problems and competencies. Pediatr Rev 2000;21: 265-271. 


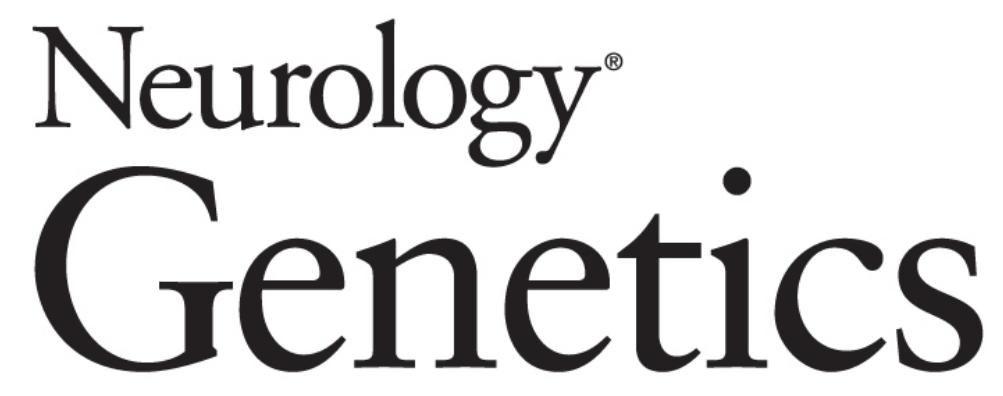

Previously unrecognized behavioral phenotype in Gaucher disease type 3 Magy Abdelwahab, Michael Potegal, Elsa G. Shapiro, et al. Neurol Genet 2017;3;

DOI 10.1212/NXG.0000000000000158

This information is current as of May 23, 2017

\section{Updated Information \& Services}

\section{Supplementary Material}

\section{References}

Citations

Subspecialty Collections

Permissions \& Licensing

\section{Reprints}

including high resolution figures, can be found at: http://ng.neurology.org/content/3/3/e158.full.html

Supplementary material can be found at: http://ng.neurology.org/content/suppl/2017/05/23/3.3.e158.DC1

This article cites 35 articles, 2 of which you can access for free at: http://ng.neurology.org/content/3/3/e158.full.html\#\#ref-list-1

This article has been cited by 1 HighWire-hosted articles: http://ng.neurology.org/content/3/3/e158.full.html\#\#otherarticles

This article, along with others on similar topics, appears in the following collection(s):

\section{EEG}

http://ng.neurology.org//cgi/collection/eeg_

Metabolic disease (inherited)

http://ng.neurology.org//cgi/collection/metabolic_disease_inherited

Information about reproducing this article in parts (figures,tables) or in its entirety can be found online at:

http://ng.neurology.org/misc/about.xhtml\#permissions

Information about ordering reprints can be found online: http://ng.neurology.org/misc/addir.xhtml\#reprintsus

Neurol Genet is an official journal of the American Academy of Neurology. Published since April 2015, it is an open-access, online-only, continuous publication journal. Copyright Copyright @ 2017 The Author(s). Published by Wolters Kluwer Health, Inc. on behalf of the American Academy of Neurology.. All rights reserved. Online ISSN: 2376-7839.

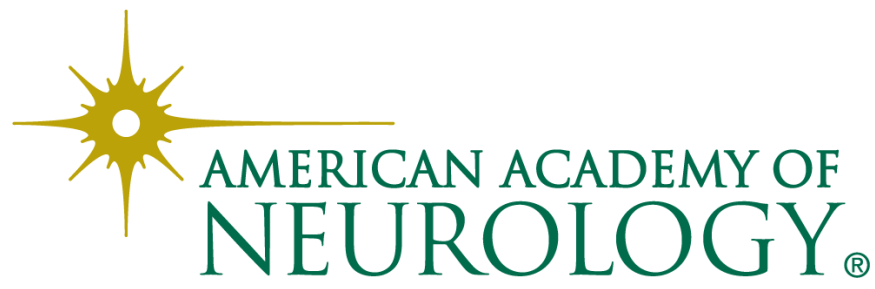

